\title{
Influence of Pore Nature on the Thermal Conductivity of Insulating Refractory Brick
}

\author{
Grace Olufunke Matthew Olajide Tunmilayo Sanya Nimota Bisola Mohammed \\ Department of Glass and Ceramics, Federal Polytechnic, P.M.B. 5351, Ado-Ekiti, Nigeria
}

\begin{abstract}
This work investigates the influence of pore nature on thermal conductivity of insulating refractory brick. The starting material used to compose the insulating bricks is kaolinite clay while saw dust of different grain sizes was used as combustible. Six sample batches of insulating brick were formulated with addition of fine saw dust particles $(0-125 \mathrm{~mm})$ and coarse saw dust particles $(154-180 \mathrm{~mm})$ at varying weight percent of 10,25 and 50 respectively. The formulated samples were mixed with solution of sodium silicate dissolved in water as binder. The mixed samples were then pressed inside mould using hydraulic pressing machine under a load of $10 \mathrm{MPa}$. The pressed samples were left to dry at ambient temperature and later sintered in an electric muffle furnace at $1000^{\circ} \mathrm{C}$. Properties such as bulk density, porosity, thermal conductivity and morphology were investigated to assess the performance of the developed insulating bricks. The results showed that porosity increases with increase in amount of saw dust particles while the bulk density decreases. However, samples with fine saw dust particles exhibited higher porosity. In terms of thermal conductivity, samples with fine saw dust particles exhibited superior thermal value of less than $0.25 \mathrm{~W} / \mathrm{mK}$ making them better suitable for insulation purpose. The morphology showed a well bonded structure of was dust within the clay matrix with several pores.
\end{abstract}

Keywords: Pore size; Thermal conductivity, Kaolinite clay, Insulating brick

DOI: $10.7176 / \mathrm{CMR} / 12-7-03$

Publication date:September $30^{\text {th }} 2020$

\section{Introduction}

Generally, bricks made of fire clay of siliceous materials are referred to as fire bricks; they are produced basically for sustaining intense heat without fusion (Vitcas, 2016). Firebricks are majorly classified into two different types depending on their porosity: insulating fire bricks and dense fire bricks. Insulating bricks are bricks with high pores which are basically utilize for insulating purposes in fire gas and electric kiln, fire boxes. Other areas of application include heat treatment furnaces as well as chamber linings. Insulating fire bricks are often made from clay products and pore forming agents such as rice husks, saw dust etc. which serve as burn-off within the insulating brick matrix to create the require pores that hold up heat flows required for insulation (Isinkaye et al., 2017).

Investigations have been carried out in previous times on the study of effects of some parameters on the performance of insulating bricks. Apeh et al. (2013) investigated the effect of temperature differences on the thermal shock behavior of Onibode fire-clay material with the addition of alumina. It was reported that thermal shock resistance of the material decreases with increasing temperature attributed to expansion and contraction of the materials at elevated and low temperatures. Davies et al. (2015) also studied the effects of firing temperature on the performances of insulating fire-bricks containing varying proportions of alumina and sawdust. It was reported that samples containing more than $20 \%$ alumina crumbled at elevated temperatures. It was still observed that the bricks performed to expectations at lower alumina contents, even at $1500^{\circ} \mathrm{C}$. The samples containing $3 \%$ sawdust and 10\% alumina, however, gave the desired requirement for preparing good insulating fire-bricks with reliable phase integrity. Michele et al. (2004) studied thermal conductivity of clay bricks. The thermal conductivity of twenty-nine samples of clay bricks developed was measured and the correlations of the thermal performance with the compositional, physical and microstructural features of products. The results observed directed our attention toward a better understanding of the role played by some parameters (i.e. mineralogical components and pore size distribution), other than bulk density, in improving or depressing the insulating properties of bricks. In view of this, the present study investigates the influence of pore nature on the thermal conductivity of insulating refractory bricks. Fine and coarse burn-off is used as pore formers which actually determine the nature of the pore formed. Tests such as porosity, bulk density, thermal conductivity and morphology were used to assess the performance of the insulating bricks.

\section{Experimental Procedure}

\subsection{Material Preparation}

The starting raw materials used to compose the insulating brick samples are kaolin and saw dust of fine and coarse particles. The as-received kaolinite clay and saw dust was used in their processed form without further purification. The as-received saw dust was sieved with a mesh to obtain fine and coarse particles. Both the kaolin and saw dust was weighed according to the sample batches shown in Table 1. The batches were mixed with sodium silicate 
solutions dissolved in water and used as binder. The mixed batches were then aged for 12 days in a cellophane nylon. After ageing, the samples were pressed using hydraulic pressing machine at a load of $10 \mathrm{MPa}$, then dry at $100^{\circ} \mathrm{C}$ for 8 hours. The dried samples were then fired at $1000^{\circ} \mathrm{C}$ for 2 hours.

Table 1. Composition of the materials in the pores size insulating bricks

\begin{tabular}{|c|c|c|c|}
\hline Samples & Clay & $\begin{array}{c}\text { Fine sawdust } \\
(0-125 \mathrm{~mm})\end{array}$ & $\begin{array}{c}\text { Coarse sawdust } \\
(154-180 \mathrm{~mm})\end{array}$ \\
\hline A & 500 & - & - \\
\hline B & 490 & 10 & - \\
\hline C & 475 & 25 & - \\
\hline D & 450 & 50 & 10 \\
\hline E & 490 & - & 25 \\
\hline F & 475 & - & 50 \\
\hline G & 450 & - & - \\
\hline
\end{tabular}

\subsection{Characterization}

The physical analysis in term of porosity and bulk density of the fired insulating brick was determined in accordance to ASTM C20-00. The morphology of the insulating bricks was examined using scanning electron microscopy (FESEM, Hitachi S-2460 N) at an accelerating voltage of $15 \mathrm{kv}$ while the thermal conductivity is measured using ASTM C-202.

\section{Results and Discussion}

\subsection{Physical Properties}

The results of the tested physical properties such as bulk density and percent porosity are shown in Table 2 . It is observed for both fine saw dust incorporated samples (B, C and D) and coarse saw dust incorporated samples (E, $\mathrm{F}$ and $\mathrm{G}$ ) that percent porosities increase significantly with increase in amount of the burn off (saw dust) in a similar trend with maximum porosity of $80 \%$ and $74 \%$ observed for samples D and G containing $50 \mathrm{wt} \%$ of fine and coarse saw dusts respectively. The highest percent pores observed for sample containing fine saw dust might be attributed to the fine particles of saw dust creating numerous fine pores. However, their bulk densities also showed similar trend as the values decrease with increase in burn off present. The decrease in bulk density can be attributed to increase in porosity as it has been established that bulk density is influenced by porosity (Gibson and Ashby, 1999). Sample A (control) without burn off has the highest bulk density with corresponding low porosity.

Table 2. Result of physical of physical properties evaluated

\begin{tabular}{|c|c|c|}
\hline Samples & $\begin{array}{c}\text { Bulk density } \\
\left(\mathrm{g} / \mathrm{m}^{3}\right)\end{array}$ & $\begin{array}{c}\text { Porosity } \\
(\%)\end{array}$ \\
\hline A & 1.675 & 38.1 \\
\hline B & 1.655 & 45.31 \\
\hline C & 1.635 & 56.01 \\
\hline D & 1.552 & 80.18 \\
\hline E & 1.652 & 45.81 \\
\hline F & 1.563 & 56.15 \\
\hline G & 1.536 & 74.00 \\
\hline
\end{tabular}

\subsection{Thermal Properties}

The results of the tested thermal properties such as thermal conductivity and thermal resistivity conducted at temperature of $50^{\circ} \mathrm{C}$ are shown in Table 3 below. It is observed for all the samples with incorporated fine and coarse saw dusts that the thermal conductivity values increase as the amount of the burn off increases indicating drastic drop in thermal resistivity of the sample insulating brick samples. Generally, the higher the porosity, the lower the density, the lower the thermal conductivity value, and the better the thermal insulating properties, without any evidence in the literature in relative to cell size (Giovanni et al., 2006). However, the results of the thermal conductivities in relation to porosities obtained in Table 4.1 do not satisfy that assertion which might be attributed to the volume of pores that is differently distributed in a limited number of large pores or in a great number of small pores, this varying distribution has been known to have significant influence on the performance and behavior of porous materials especially thermal conductivity (Giovanni et al., 2006). Nevertheless, sample bricks $\mathrm{A}-\mathrm{E}$ are considered for applications as heat insulating materials as their thermal conductivities fall lower than $0.25 \mathrm{~W} / \mathrm{mk}$ (Brusatin et al, 2004) while according to CEN (1998) all the samples are considered for heat insulating materials as their thermal conductivities fall within standard range of $0.023-2.9 \mathrm{~W} / \mathrm{mk}$ for construction and heat insulating materials. Sample A without burn-off showed better thermal conductivity and resistivity value. 
Table 3. Result of thermal conductivity evaluated

\begin{tabular}{|c|c|c|}
\hline Samples & $\begin{array}{c}\text { Thermal Conductivity } \\
(\mathrm{W} / \mathrm{mk}) \text { at } 50^{\circ} \mathrm{C}\end{array}$ & $\begin{array}{c}\text { Thermal Resistivity } \\
(\mathrm{mk} / \mathrm{W})\end{array}$ \\
\hline $\mathrm{A}$ & 0.139 & 7.19 \\
\hline $\mathrm{B}$ & 0.181 & 5.52 \\
\hline $\mathrm{C}$ & 0.183 & 5.46 \\
\hline $\mathrm{D}$ & 0.188 & 5.32 \\
\hline $\mathrm{E}$ & 0.216 & 4.63 \\
\hline $\mathrm{F}$ & 0.294 & 3.40 \\
\hline $\mathrm{G}$ & 0.313 & 3.19 \\
\hline
\end{tabular}

\subsection{Morphology}

The results of the selected samples A, D and G were shown in Figures $1(\mathrm{a}-\mathrm{c})$. Representative samples were selected since there is no much difference in their morphology. Figure 1(a) indicates the SE image of sample A (control) without burn off; it is observed that a well packed structure is obtained with lateral crack on the surface. This well packed structure with even dispersed grains might be responsible for its bulk density while the EDS (Energy Dispersive Spectroscopy) spectrum indicating predominant element Si (silicon) and Al (aluminum) showed it is an aluminosilicate compound thus account for its better thermal properties. However, Figures 1(b) and (c) for samples D (containing $50 \mathrm{wt} \%$ fine saw dust) and $\mathrm{G}$ (containing $50 \mathrm{wt} \%$ coarse saw dust) showed similar microstructure characteristics with well bonded structure of saw dust within the clay matrix. However, pockets of several pores can be observed within the structure indicate space left behind by the burn off after firing. The observed morphology however dictates the performance of the properties tested in all the sample bricks containing burn off studied in this project. The EDS for samples with burn off also showed predominant elements of Si (silicon) and $\mathrm{Al}$ (aluminum) which indicate they are all aluminosilicate refractory materials. The relative increase in iron $(\mathrm{Fe})$ content might be attributed to increase in amount saw dust incorporated as this burn off contains appreciable iron content.

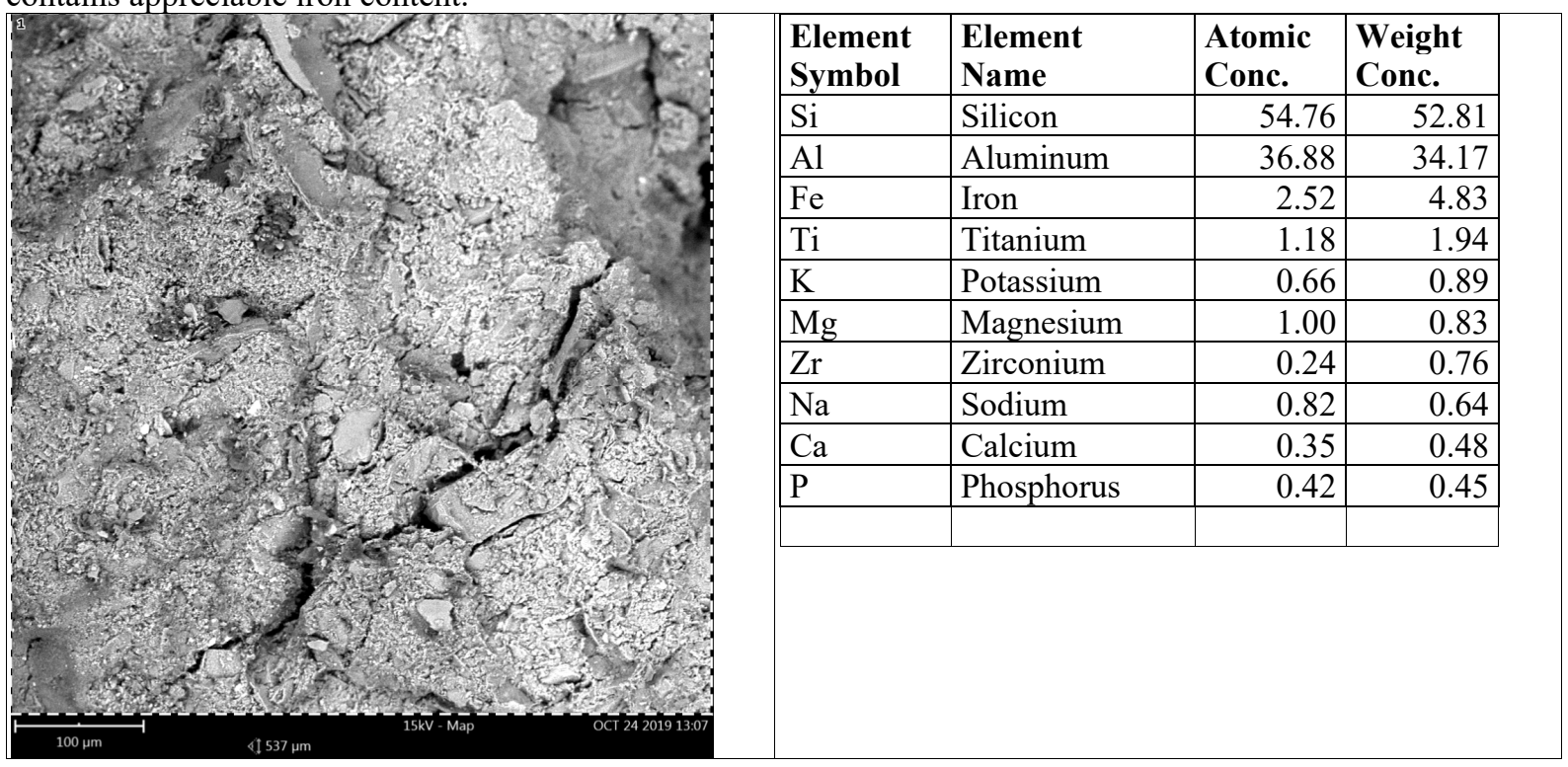



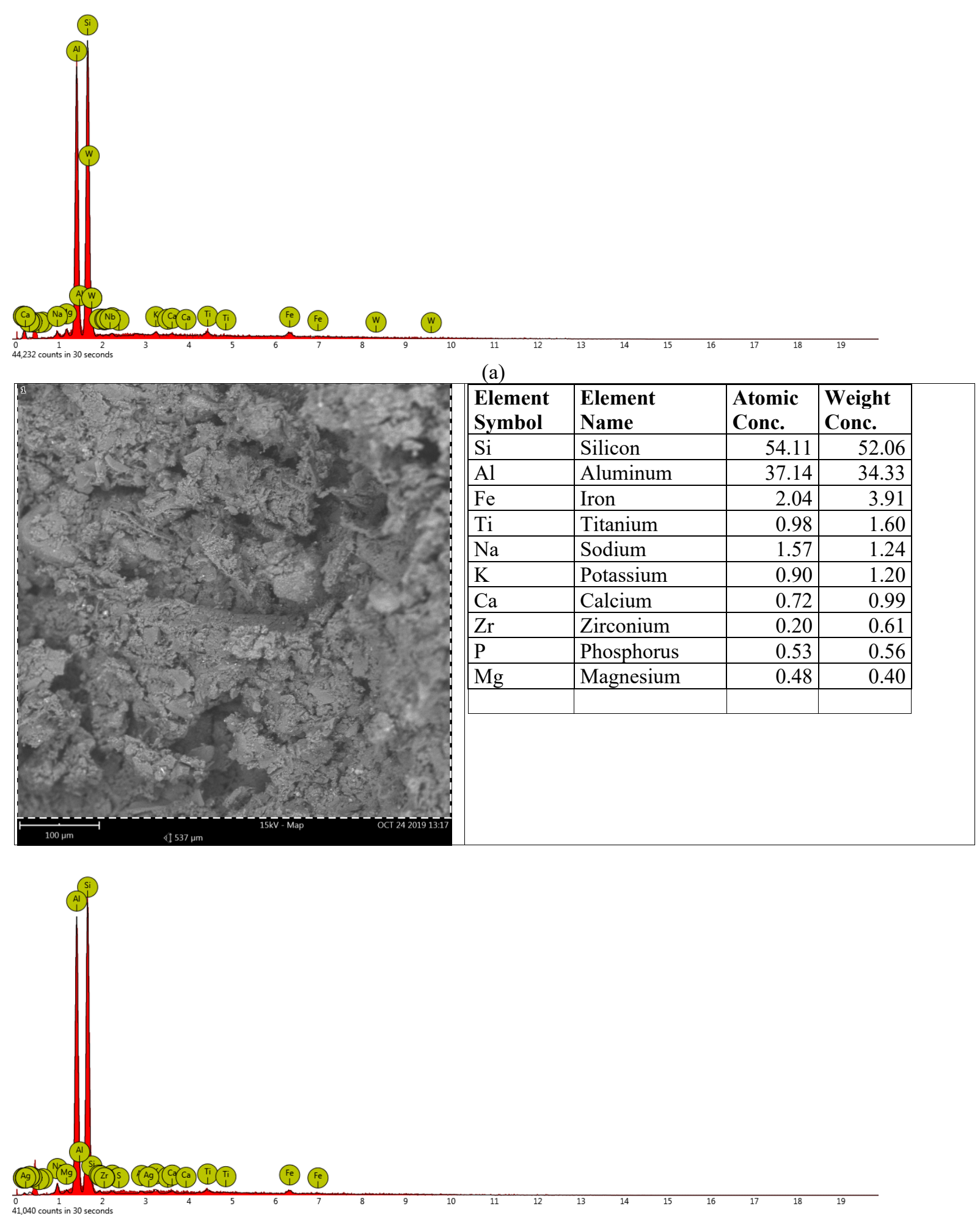

(b) 


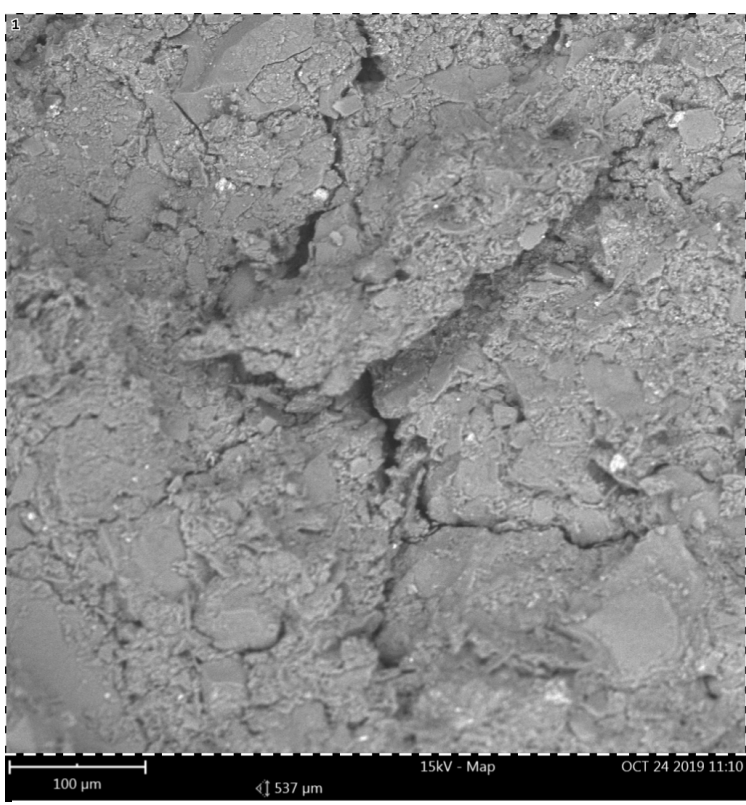

\begin{tabular}{|l|l|r|r|}
\hline $\begin{array}{l}\text { Element } \\
\text { Symbol }\end{array}$ & $\begin{array}{l}\text { Element } \\
\text { Name }\end{array}$ & $\begin{array}{l}\text { Atomic } \\
\text { Conc. }\end{array}$ & $\begin{array}{l}\text { Weight } \\
\text { Conc. }\end{array}$ \\
\hline $\mathrm{Si}$ & Silicon & 47.19 & 41.78 \\
\hline $\mathrm{Al}$ & Aluminum & 37.02 & 31.49 \\
\hline $\mathrm{Fe}$ & Iron & 4.82 & 8.48 \\
\hline $\mathrm{Ti}$ & Titanium & 2.21 & 3.33 \\
\hline $\mathrm{Zr}$ & Zirconium & 0.98 & 2.82 \\
\hline $\mathrm{K}$ & Potassium & 1.22 & 1.50 \\
\hline $\mathrm{Ca}$ & Calcium & 1.13 & 1.43 \\
\hline $\mathrm{Mg}$ & Magnesium & 0.92 & 0.71 \\
\hline $\mathrm{Na}$ & Sodium & 0.79 & 0.57 \\
\hline $\mathrm{P}$ & Phosphorus & 0.25 & 0.25 \\
\hline
\end{tabular}

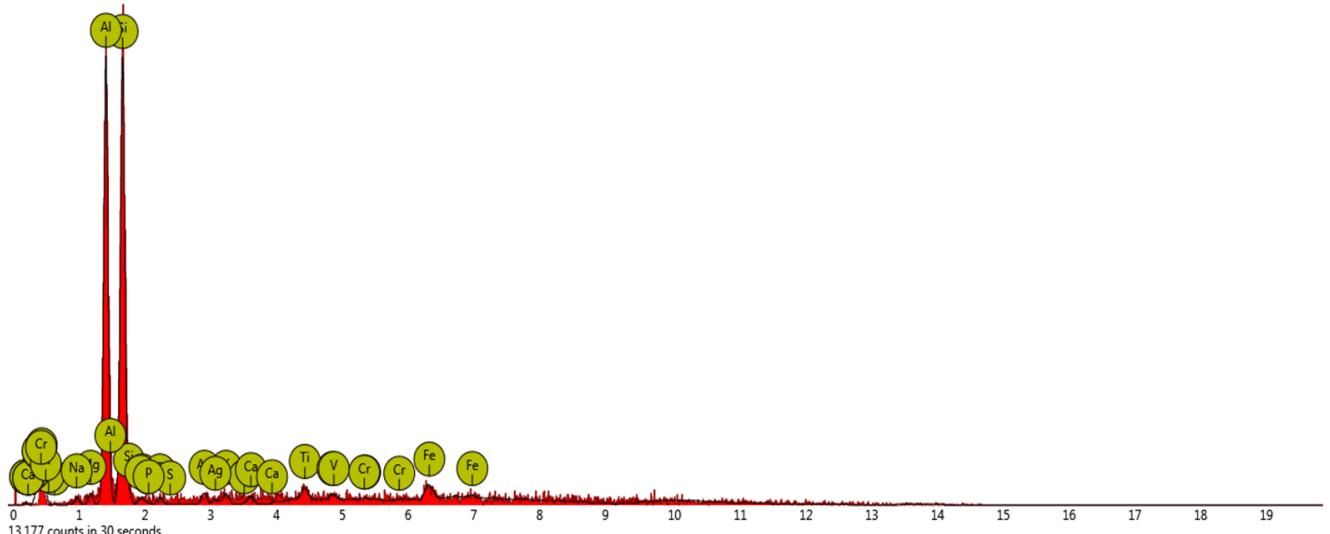

(c)

Figure 1. SEM/EDS of (a) Sample A with 0\% saw dust (b) Sample D with 50\% saw dust (c) Sample G with 50\% saw dust.

\section{Conclusion}

In this present work, investigation was carried out on the influence of pores (porosity) on the thermal conductivity of clay matrix containing combustible (saw dust) intended for application as insulating bricks. The following conclusions were drawn within the limit of the results obtained in this work:

- The inclusions of saw dust initiated pores in the clay matrix which increases as the amount of the saw dust increase with maximum porosity values of $80 \%$ and $74 \%$ obtained for insulating brick containing $50 \%$ fine and coarse saw dusts respectively.

- The fine saw dusts enhance formation of small and numerous pores unlike coarse saw dusts thereby enhancing better thermal values observed for samples B, C and D.

- Thermal conductivities value increases across all the samples despite the significant increase in porosity thus are not influenced by pores which might be attributed to the volume of pores differently distributed in a limited number of large pores or in a great number of small pores.

- All the developed samples satisfy thermal conductivity values to be considered for heat insulating materials as they fall within standard value of $0.023-2.9 \mathrm{~W} / \mathrm{m} . \mathrm{K}$ for construction and heat insulating materials.

- Considering the thermal conductivity and resistivity behavior of all the samples, the bricks can only be recommended for heat insulation in drying ovens which are not exposed to extreme firing temperatures.

References

Apeh, F.I., Esezobor, D.E., Lawal, G.I., Adeosun, S.O. \& Agunsoye, J.M. (2013), “The Effect of Temperature 
Difference on the Thermal Shock Behavior of Onibode Fire-Clay material with the addition of Alumina", The International Journal of Eng. and Sci., 84-87.

Brusatin, G., Bernardo, E. \& Scarinci, G. (2004). "Production of foam glass from glass waste", Proc. of the Int. Conf. on Sustainable Waste Manag. and Recycling Glass Waste, 67 - 82.

Davies, O. F., Fatai, O. A., Peter, O., \& Joseph, O. B. (2015). "The effect of firing temperatures on the performance of insulating firebiricks containing different proportion of alumina and sawdust, J. of Miner. and Mater. Characterization and Eng., 309-317.

European Committee for Standardization (1998). "Acoustics-determination of sound absorption coefficient and Impedance in impedances tubes-Part 2: transfer-function method". ISO10534-2, CEN, Brussels, Belgium (1998).

Gibson, L.J. \& Ashby, M.F. (1999). “Cellular Solids: Structure and Properties”, Cambridge University Press.

Giovanni, S., Giovanna, B. \& Enrico, B. (2006). "Glass Foams//Cellular Ceramics: Structure, Manufacturing, Properties and Applications", Wiley-VCH Verlag GmbH \& Co. KGaA, 158-176.

Isinkaye, E.O., Shado, A.S. \& Sanya, O.T. (2017), "Development and Characterization of Rice husk Insulating Bricks from Two Selected Deposits in Ekiti State, Nigeria", Int. J. of Sci. and Res., 132-138.

Michele, D., Francesca, M., Paolo, P., Mariarosa, R., Giorgio, Z. (2004). "Thermal conductivity of clay bricks", J. of Mater. in Civil Eng., 8-24.

Vitcas. (retrieved 08 7, 2016). insulating fire bricks. http://ww.vitcas.com/refractorybricks. 